\title{
Analysis on the Daofu Tibetan Color Painting Style for Residence Interior Decoration-Interaction of Tibetan and Han Culture
}

\author{
Xia Ling, Feihu Chen* \\ School of Design, Hunan University, Changsha, 510006, China \\ * Corresponding Author: Feihu Chen
}

Keywords: Tibetan and Han culture; interaction; Tibetan residence; painting

\begin{abstract}
The residence interior decoration of Tibetan Daofu County of Sichuan province were studied from the analysis of the overall composition, painted patterns, colors etc., and the blending characteristics of Tibetan and Han culture. Daofu Tibetan and Han painting process is the communication and integration of Tibetan and Han ethnic culture in acculturation, showing non-confrontational natural adaptation. Whether historical or contemporary, Daofu Tibetan residence interior decoration has always been to an open attitude in the existence and development.
\end{abstract}

\section{Introduction}

Daofu County, the heart of Kangba, is located in the northeast of Ganzi city in Sichuan province, as well as the key point to the counties along Kangba road and Tibetan.It is not only the border area of Tibetan culture, but also the border area of Chinese culture. The Kangba region plays an important role in the propagation of Tibetan Buddhism in economic and political, especially the development of Tibetan Buddhism on "post-hongjin period" began in Kangba [1].

The ancient xiangwu of Daofu County is located in the core area of the tibetan-yi corridor, which realized the communication between the north and the south of China. The location of human geography determines the multi-ethnic cultural system in which dafu is dominated by Kangba Tibetan culture [2].

As early as the yuan dynasty, outland culture entered the kang district. In the seventh year of yongzheng, the qing government build the "Huiyuan temple", moved the seventh dalai lama from Lhasa to the city of gerda (now Hede town of Daofu county), and stationed troops in tucheng (now Daofu county). In the three years of Xuantong, Daowu "restored land to flow" and abolished the chieftain system. In the second year of the republic of China, Daowu county was renamed Daofu county, and Xikang built a province, Chinese culture began to take a place in kangqu.Dafu county is located at the first stop of the 318 national highway into Tibet,it is a typical Tibetan town formed by the combination of the tusi garrison and the traffic fortress. Due to the station of tusi and other reasons, its folk dwellings have continued the typical Tibetan style. In the whole Tibetan area of western Sichuan, the concentration function and delicacy of the Daofu folk dwellings are unmatched in other areas [3].

\section{The Model of Tibetan and Han Cultural Interaction}

For a long time, the Tibetan residential buildings have been restricted by the religious hierarchy system and have always been characterized by simplicity. With the development of society and economy, as well as local government policy guidance for the development of tourism under the influence of many factors, the new Tibetan dwellings appeared. The architectural decoration of the new Tibetan folk house basically follows the aesthetic interest of the Tibetan buddhist art tradition and reflects the principle of the supremacy of religious meaning. The biggest characteristic of this kind of new Tibetan folk house is that it realizes the folk culture of temple architecture and integrates the great success of traditional Tibetan architecture. It can be said that the secularization of temple architecture or the religion of folk house architecture are the artistic foundation of this kind of new 
Tibetan folk house. [4] The new Tibetan folk house contains the religious concept, traditional value concept and cultural connotation of the Tibetan national tradition. The Tibetan folk houses in Dafu County have formed their own tourism characteristics and become the tourist attractions that the government focuses on and are known as "the hometown of the art of Tibetan houses". The rise of new folk houses reflects the advantages of architecture, culture and market.

Take the tibetan-style residential buildings built on the mountain in Guanxianshui town, Daofu County as an example. Daofu is located in the Xianshui river fault zone and has a history of frequent earthquakes. In particular, in 1981, the Daofu earthquake caused the collapse of all homes in Xianshui town. The government set up a homestead reconstruction team to organize the reconstruction of dwellings. At the beginning of the reform and opening up in the 1980s, the government encouraged the mining of gold and built a forest farm in Dafu County for timber production and processing. [5] The new Tibetan residence of dreyfus quickly reached the peak after completing functions such as earthquake prevention and residence. The average family spends several years, spending tens of millions of dollars to build a decapitated building and decorate it with painted and carved beams like a monastery building. With the comprehensive opening up of Tibetan areas in western Sichuan and the booming development of tourism industry, the new Dafu Tibetan residence has become the object of people's appreciation and experience, and it is also a typical example of the interaction between Tibetan and Chinese cultures. (Figure 1)

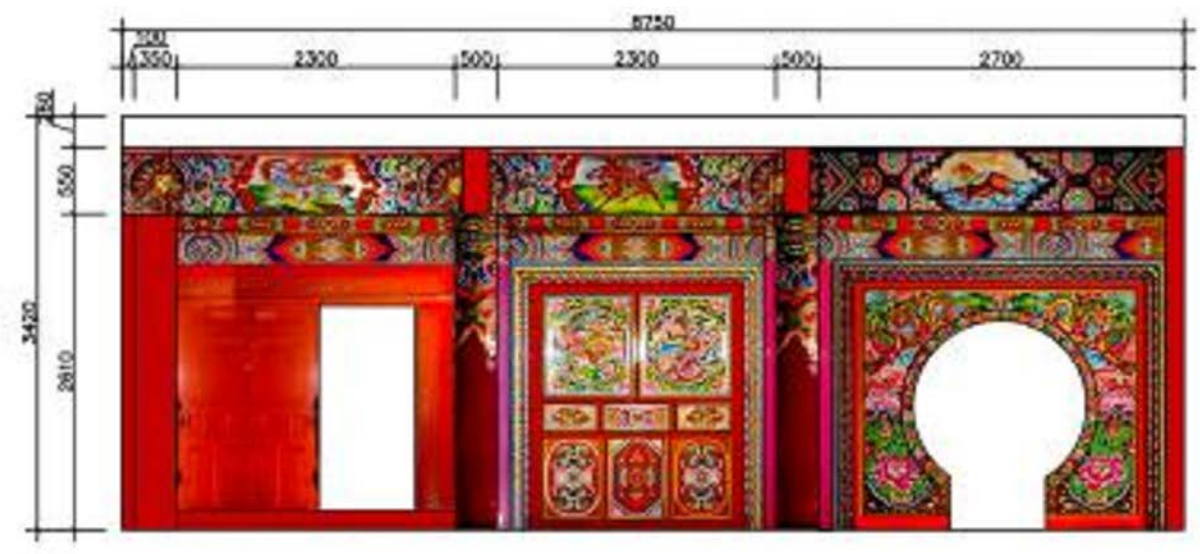

Figure 1. A elevation of sitting room 1 (Tibetan indoor mapping for residence interior decoration in Xianshui town of Daofu county drawn by the author)

\section{The Mixed Characteristics of Tibetan and Han Culture in Interior Decoration of Daofu Tibetan Dwellings}

\subsection{Color Painting Composition Shows the Characteristics of Tibetan and Han Cultural Integration.}

The tunfu Tibetan residence is a "collapse" structure, which consists of two floors of space and is aligned up and down. From each pillar to the roof at the bottom, the columns form a uniform and uniform space, which is composed of wooden columns, wooden beams and crossbeams. These large logs are painted and decorated in all shapes. Beam is the superposition construction method of two beams, forming the large and small beam. The color painting on the beam includes the proportion relation of the "three pavilion" structure of the han type mingqing color painting and the composition of the center of the beam. Because the dreyfus Tibetan dwellings are painted on the whole interior interface, the painted ends of the beams do not have hoop heads, but use diamond hard boxes to connect the two sides of the turn, forming a continuous and rhythmic visual effect. On the basis of the "three pavilions" structure of the han Ming and Qing dynasty color paintings, the indoor color painting of the duofu Tibetan dwellings has changed a lot. On the same wooden structure, multiple beams are repeated continuously, and the pattern connecting the beams becomes the pattern between the beams. Some wood structure on the continuous pattern and the center of the beam frame 
combination, there are also continuous patterns and the package frame combination. With the change of The Times, the pattern structure is becoming more and more complicated. On the basis of the principle of left and right symmetry, there is no strict standard for the style of qingguan color painting, and the color painting composition is more free.

The interior interface of drefu Tibetan dwellings is decorated with color painting, which reflects the structure of stucco paintings in the Qing dynasty. The painting originated in the late Qing dynasty was painted on the visible parts of the building. However, on the basis of the han style and Qing dynasty sea stucco painting, the interior color painting of the dafu folk house has evolved from strict and neat to rich and delicate, and the pattern structure has the characteristics of fusion and denseness. The upper end of the inner wall of the drefu Tibetan dwellings is often used to draw curtain curtains by means of fainting. In the middle, there are continuous patterns of jewelry net (Figure 2). This combination of the typical patterns of Tibetan and Chinese shows the changes of the official color painting style of Qing dynasty by local craftsmen.

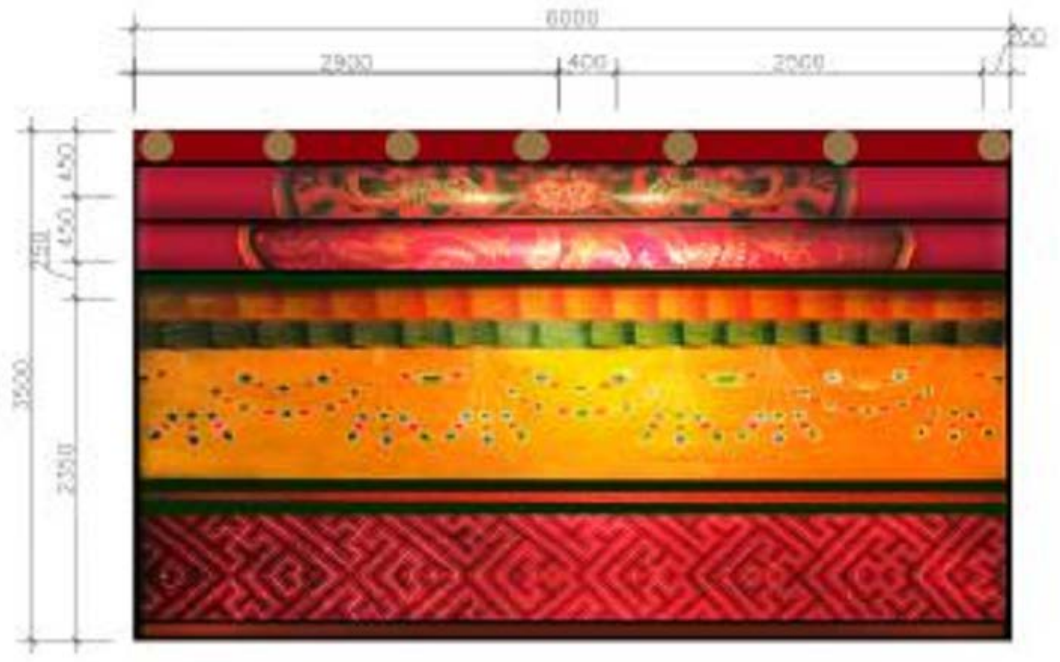

Figure 2. A elevation of bedroom

\subsection{The Application of Patterns Reflects the Compatibility of Tibetan and Han Culture.}

Religious conformity is the hidden cultural motivation of Tibetan architectural color painting patterns, covering the customs and beliefs of the Tibetan people. Daofu Tibetan houses painted pattern has the characteristic of variety, symbolization, stylized, good at in a different part of the building use different design, the decoration pattern of Tibetan Buddhism to occupy the main body of coloured drawing or pattern, but the temple coloured drawing or pattern that is commonly used in the image of Buddha, king kong, tara was not applied in ordinary homes, number, confused, but rather by a variety of animals, plants and implements lines is given priority to, content is the Buddha more sweet, sanbao pearl west grass (lucky grass), lotus, treasure flowers, snow lion, golden wings bird, blessing of longfeng lines and other religious and the meaning of the pattern. The words such as the collection of religious incantation in Sanskrit are both religious and decorative, and are an important decorative pattern for interior painting. The color patterns of dref Tibetan dwellings are not only diverse in theme types and styles, but also varied in combination. Most of the patterns are mainly suitable for patterns, and the composition of the pictures often adopts four directions continuous and two directions continuous. The patterns are interspersed and staggered by geometric segmentation, in an orderly and rhythmic manner.

Traditional Chinese auspicious patterns, such as auspicious clouds of dragon and phoenix, bats, unicorn, shouzi, magpie, crane, twig flowers, brocade, landscape flowers and birds, etc., have been collected and stored by the colorful paintings of the folk houses of Daofu. The inner wall of the dafubuonko building is divided into two parts by 10 or so tree trunks, which are polished and even embedded in the vertical groove of the pillar to form the wooden rib wall. The wooden rib wall is painted vermilion with vermilion paint, and decorated with bat and group Chinese characters with 
gold, which is very ethnic and decorative (Figure 3).

The decorative pattern of the indoor color painting of the duofu Tibetan folk house not only has the traditional national artistic style, but also has the strong religious artistic flavor. The color pattern theme reflects the combination of the form of Chinese color painting and the content of Tibetan Buddhism, and its development reflects the characteristics of the integration of diverse cultures.

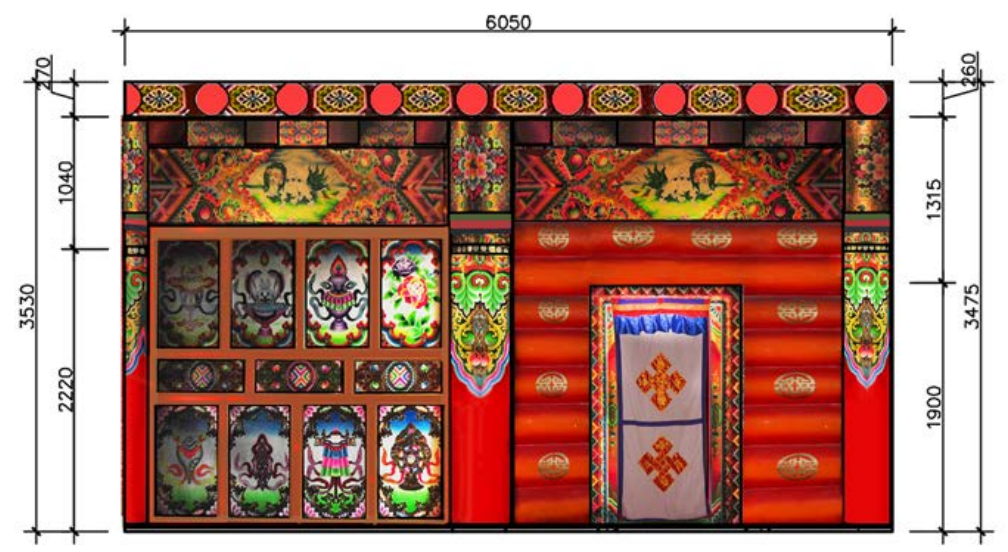

Figure3. A elevation of sitting room 2

\subsection{Color Painting Shows the Communication and Integration of Tibetan and Han Culture.}

The Tibetan painting art represented by tangka has a high artistic achievement, and the decoration of the taofu Tibetan residential buildings is mainly colored with colorful painting. The main color is red and gold, supplemented by Tibetan green, deep and gorgeous, and the artistic style is mysterious and enthusiastic. Daofu Tibetan houses painted color difference Yu Hanshi distinctive characteristics of painting in the Ming and qing dynasties, the Ming and qing dynasties of han type coloring is green color is cool color to move, and Daofu Tibetan dwellings predominantly red coloured drawing or pattern of warm color attune, turquoise is only an ornament, warm color attune to make indoor space appear bright and warm, this is is located in the cold area Tibetan in harsh natural environment and the lack of material conditions, forming the colour and aesthetic temperament and interest.

The qing dynasty paintings of han style used a large amount of gold coating technology. The powder was first drained at all the gold patches to make the color painting patterns protrude from the surface of components, forming a three-dimensional effect similar to that of shallow relief. The decorative method of leaching powder and piling gold in jin qing dynasty paintings of han dynasty is widely used in the color painting of drefu Tibetan folk houses. A lot of gold is used in color painting to decorate, emphasize composition with gold line, dot gold and small piece gold if numerous stars scatter everywhere, foil color drawing design to form golden and blue brilliant effect. The painted lines of drefu Tibetan folk houses are neat and delicate, the color is rigorous and rich, and the indoor atmosphere is more and more intense and noble.

Different from the strict color rendering system of han style painting from Ming dynasty to qing dynasty, the color painting of Tibetan style houses of Daofu nationality, under the color concept of Tibetan nationality's religious characteristics and aesthetic psychology as the principle, has carried out the micro color adjustment on the basis of following the standard, which reflects the rich creativity and subjective initiative of Tibetan artisans.

\section{The Interaction between Tibetan and Han Exchanges from the Interior Decoration of Daofu Tibetan Dwellings}

Daofu is typical of the tusi stationed and traffic fortress double factors work together to form a Tibetan towns, is the culture of the nomadic culture and farming culture mutually parallel, humanistic geography determines the Daofu in kangba Tibetan culture as the main body of the national culture system, Tibetan and the inherent relationship, in the history of the dispute and the exchange, and the Tibetan and han on the geopolitical integral sex, determines the impact of Tibetan culture to each 
other and development is bidirectional.

As early as the qing dynasty, the communication between Tibetan and Chinese cultures was quite frequent, and the cultural exchange inevitably led to imitation of artistic and cultural forms. The fusion of Tibetan architectural painting and han painting resulted in the change of local color painting styles. Chinese culture influences Tibetan culture, but after the formation of stable form of Tibetan architectural color painting, with the wide spread of Tibetan Buddhism, it also affects architectural color painting in other areas. The shadow of Tibetan culture can also be found in the patterns of official color paintings in the qing dynasty, which is the result of the cultural exchanges between ethnic groups. It is also the natural adaptation process of Tibetan and han cultures showing non-antagonism in culturation.

As a treasure of Tibetan culture, traditional Tibetan residential building decoration should not only be stimulated by fresh factors, but also emphasize local transformation and innovation. It should be said that no matter history or contemporary times, traditional Tibetan residential building color painting always exists and develops in an open and diversified manner.

\section{Conclusion}

The development of modern Tibetan-style residential building decoration is accompanied by the synchronous development of the architecture and art of the Tibetan nationality. In the process of development, it integrates technology, materials and technology and continuously reaches a peak. The ethnic and religious culture carried by the Tibetan residential buildings also makes it of high development value and reality. However, the new folk house is not the end of Tibetan architectural art, and there are still many aspects that need to be improved. As a cultural heritage, Tibetan residential decoration has its inherent evolution rule, which should be scientifically recognized and effectively guided and managed to improve its architectural decoration style and develop its cultural advantages in a more professional way.

\section{Acknowledgement}

The paper is the phased achievement of the national social science foundation art project (15EG181) and the special fund project of the central university basic research service fee (2016SGJPY01).

\section{References}

[1] Ding J Z. A Comparative Study of Han and Tibetan Views of Death[J]. Comparative Civilizations Review, 2016, 74(74): 3.

[2] Luo L P, Liu Y, Liu Y. Spirituality Matters: The Role of Religion in Development Project Evaluation in the Tibetan Communities in China[J]. New Directions for Evaluation, 2018, 2018(159): 97-105.

[3] McConnell F. Reconfiguring diaspora identities and homeland connections: the Tibetan 'Lhakar'movement[J]. Dismantling Diasporas: Rethinking the Geographies of Diasporic Identity, Connection and Development, 2015: 99-111.

[4] Yu B, Xu L, Wang X. Ecological compensation for hydropower resettlement in a reservoir wetland based on welfare change in Tibet, China[J]. Ecological Engineering, 2016, 96: 128-136.

[5] Feng L, Lu X, Yu Y, et al. Survey, culture, and genome analysis of ocular Chlamydia trachomatis in Tibetan boarding primary schools in Qinghai province, China[J]. Frontiers in cellular and infection microbiology, 2017, 6: 207. 